\title{
Arsenite, arsenate and vanadate affect human erythrocyte membrane
}

\author{
Tian-Lan Zhang a , Yu-Xi Gao ${ }^{\text {b }}$, Jing-Fen Lu ${ }^{\mathrm{c}}$, Kui Wang a,c,* \\ ${ }^{a}$ Department of Bioinorganic Chemistry and Inorganic Pharmaceutical Chemistry, Beijing Medical University, Beijing 100083, PR China \\ ${ }^{\mathrm{b}}$ Research Center for Eco-environmental Sciences, Chinese Academy of Sciences, Beijing 100085, PR China \\ ${ }^{\mathrm{c}}$ National Research Laboratories of Natural and Biomimetic Drugs, Beijing Medical University, Beijing 100083, PR China
}

Received 21 May 1999; received in revised form 6 September 1999; accepted 10 September 1999

\begin{abstract}
Effects of arsenite, arsenate and vanadate on human erythrocyte membrane have been assessed according to their routes passing through the membrane, their binding modes to the membrane and their influences on membrane proteins and lipids. The uptake of arsenate (1.0 mM) by cells approached a limit with intracellular arsenic of about $0.2 \mathrm{mM}$ in $5 \mathrm{~h}$, and was strongly inhibited ( $\sim 95 \%)$ by $4,4^{\prime}$-diisothiocyano$2,2^{\prime}$-disulfonic stilbene (DIDS), indicating that arsenate, similar to vanadate, passed across the membrane through the anion exchange protein, band 3. Arsenite $(1.0 \mathrm{mM})$ influx reached a maximum of about $0.4 \mathrm{mM}$ in $30 \mathrm{~min}$, and was not inhibited by DIDS. The transformed species of arsenite bound to the membrane from cytosol. In contrast, arsenate bound rapidly from the outside, followed by releasing and re-binding. The binding to the membrane via sulfhydryl was indicated by the decrease of the sulfhydryl level of membrane proteins. Polyacrylamide gel electrophoresis in sodium dodecyl sulfate (SDS-PAGE) analysis revealed that the proteins, bands 1-3, were among the targets of arsenite, arsenate and vanadate. Their binding to the membrane also induced changes in the fluidity of membrane lipids and in the negative charge density in the outer surface of the membrane. (C2000 Elsevier Science Inc. All rights reserved.
\end{abstract}

\section{Introduction}

The enthusiasm to develop arsenic-based drugs has never subsided though arsenic compounds are toxic and carcinogenic [1-3]. Since arsenite has recently been found effective in the treatment of leukemia by inducing cell apoptosis [47], arsenic compounds are drawing more attention from both toxicological and medicinal circles.

The metabolism of arsenite and arsenate, the main forms of inorganic arsenic compounds in aqueous solutions, has been extensively studied [1]. In bacterial systems, As(V) is reduced to As(III) by an arsenate reductase and As(III) is extruded by an ATPase-dependent pump [8,9]. In humans and most other mammals studied, As(V) is reduced enzymatically in the blood and the produced As(III) is then methylated twice in hepatocytes under the catalysis of respective enzymes [10-13]. Lung and kidney, in addition to liver, may also be the sites of methylation [14]. The main methylation products, monomethylarsonate (MMA) and dimethylarsinate (DMA), have very low affinities for macromolecules and are rapidly excreted [14].

\footnotetext{
* Corresponding author. Tel.: + 86-10-6209-1539; fax: + 86-10-62015584; e-mail: wangkui@mail.bjmu.edu.cn
}

While an arsenic compound is bio-transformed, the relevant biological system, especially the cells involved, is also affected. Since the detoxification mechanism varies with biological species and since the fate of an arsenic compound varies with the tissues in which the compound exists, it would be more direct to use human cells than other cells in assessing the effect of arsenite and arsenate on the human body. The toxicity of these compounds to human cells, and particularly to human erythrocytes, was not evaluated until most recently [15]. Erythrocytes are the first target that an arsenic compound attacks in the body after systemic absorption [13], and the cell membrane is the frontier facing the attack. In human erythrocyte membrane (HEM), there are more than 20 kinds of proteins, of which some are critical enzymes [16]. The protein concentration in the membrane is comparable with that in the cytosol. Therefore, the interaction between these arsenic compounds and HEM is an important part of their bio-effects. The aim of the present study was to assess the effects of arsenite and arsenate on HEM. We attempted to seek answers to the following questions: What is the difference in the route which arsenite and arsenate take to pass through the membrane? Do they bind to the membrane? Which protein (s) do they bind to and influence? Which properties of the membrane are affected? Since both arsenate and 
vanadate are phosphate analogs $[15,17-20]$ and vanadate, by itself, exhibits some important physiological effect [21], we also studied vanadate for comparison.

\section{Experimental}

\subsection{Materials and solutions}

Human blood was donated fresh from a volunteer.

Sodium metaarsenite $\left(\mathrm{NaAsO}_{2}\right)$, disodium arsenate $\left(\mathrm{Na}_{2} \mathrm{HasO}_{4} \cdot 7 \mathrm{H}_{2} \mathrm{O}\right)$ and sodium metavanadate $\left(\mathrm{NaVO}_{2}\right.$. $\left.2 \mathrm{H}_{2} \mathrm{O}\right)$ of analysis grade, and ultra pure sulfuric acid and nitric acid (As $\leq 0.01 \mathrm{ppm}$ ) for sample digestion were all from Beijing Chemicals. 4,4'-Diisothiocyano-2,2'-stilbene disulfonic acid (DIDS), acrylamide, sodium dodecyl sulfate (SDS), 2-amino-2-(hydroxymethyl)-1,3-propandiol (Tris), bovine serum albumin (BSA), 5,5'-dithio-bis(2nitrobenzoic acid) (DTNB), and 5- and 16-doxyl stearic acids (5DS and 16DS) were all from Sigma. Molecular weight markers were from Lizhu Dongfeng Biotech. Co., Shanghai. $N, N^{\prime}$-Methylenebisacrylamide (Bis) was from BRL. All other chemicals used were of analysis grade.

Solutions were: $5 \mathrm{P} 8$ ( $5 \mathrm{mM}$ sodium phosphate at $\mathrm{pH} 8.0$ ); PBS ( $150 \mathrm{mM} \mathrm{NaCl}, 10 \mathrm{mM}$ phosphate and $2 \mathrm{mM} \mathrm{D}$-glucose, $\mathrm{pH} 7.4$ ); low ionic strength isotonic buffer, LISIB (10 mM phosphate, $302 \mathrm{mM}$ D-glucose, $\mathrm{pH}$ 7.4).

5P8, PBS, LISIB, DIDS, DTNB and solutions for polyacrylamide gel electrophoresis were freshly prepared. Stock solutions of As( III), As( V) and V(V) in PBS were stored in a refrigerator $\left(0-4^{\circ} \mathrm{C}\right)$ and always checked before use to ensure that they were clear.

\subsection{Transport and binding kinetics}

Freshly drawn human blood was mixed with three volumes of $0.9 \%(\mathrm{w} / \mathrm{v}) \mathrm{NaCl}$ and centrifuged, and the supernatant, fat, lymphocytes and leukocytes were removed. After rinsing twice with PBS, the erythrocytes were suspended in PBS at a hematocrit of $40 \%(\mathrm{v} / \mathrm{v})$. Cells in final solutions were counted in a hemocytometer. For inhibition experiments, DIDS was added at this stage, and the mixture was incubated at $36 \pm 1^{\circ} \mathrm{C}$ for $30 \mathrm{~min}$. The final solution contained $125 \mu \mathrm{M}$ DIDS (for inhibition experiments only), $1 \mathrm{mM} \mathrm{AsO}_{3}{ }^{3-}$ or $\mathrm{AsO}_{4}{ }^{3-}$ and $5 \times 10^{8}$ cells $/ \mathrm{ml}$ erythrocytes. In transport experiments, no DIDS was added. The transport and inhibition experiments were performed by following the procedure described by Cantley et al. [17] with some alteration in the method to determine the amount of arsenic, i.e. the intact cells, the separated lysate and the washed membrane were individually digested with $\mathrm{H}_{2} \mathrm{SO}_{4}$ and $\mathrm{HNO}_{3}$ before the determination of arsenic content using an atomic absorption spectrophotometer (YL-110, Beijing) equipped with a hydride formation system (WXF-1C, Beijing).

\subsection{Determination of hemolysis}

Hemolysis might affect the amount of arsenic in cytosol and membrane. Thus, parallel experiments were run to evaluate the percent hemolysis $\mathrm{H} \%$ in the absence and presence of arsenite, arsenate and vanadate, respectively. The incubation procedure was basically the same as that for transport experiments. After each incubation, the suspension was centrifuged at $3000 \mathrm{~g}$ for $90 \mathrm{~s}$ and the supernatant taken for absorbancy measurement on a 721 spectrophotometer (Shanghai, China) at $540 \mathrm{~nm}$ with PBS as the reference. An aliquot of the erythrocyte suspension was added to 49 volumes of ice-cold deionized water and stirred vigorously. After centrifugation at $20000 \mathrm{~g}$ for $30 \mathrm{~min}$, the supernatant was separated and its absorbancy at $540 \mathrm{~nm}$ was determined as a measure of the complete release of hemoglobin $\left[\left(A_{540}\right)_{\mathrm{cr}}\right]$. The percent hemolysis was calculated according to Eq. (1):

$$
\begin{aligned}
\mathrm{H} \% & =100\left(A_{540}\right)_{\mathrm{sample}} /\left[50\left(A_{540}\right)_{\mathrm{cr}}\right] \\
& =2\left(A_{540}\right)_{\mathrm{sample}} /\left(A_{540}\right)_{\mathrm{cr}}
\end{aligned}
$$

\subsection{Preparation of erythrocyte ghosts and protein assay}

White ghosts were prepared according to Ref. [22]. All procedures were conducted at $2-4^{\circ} \mathrm{C}$ or on ice. Protein content was determined by the method of Lowry et al. [23], using bovine serum albumin as the standard.

\subsection{Determination of sulfhydryl in the membrane}

After incubation of erythrocyte ghosts ( $1 \mathrm{mg}$ protein $/ \mathrm{ml}$ ) with $1.0 \mathrm{mM}$ arsenite, arsenate and vanadate, respectively, at $36 \pm 1^{\circ} \mathrm{C}$ for $8 \mathrm{~h}$, the sulfhydryl content in the membrane was determined according to Ellman's method [24]. To eliminate, or at least alleviate, the possible interference of the excess arsenic and vanadium species, the suspension was centrifuged and the supernatant removed before the addition of DTNB.

\subsection{Polyacrylamide gel electrophoresis in sodium dodecyl sulfate (SDS-PAGE)}

Discontinuous polyacrylamide gel electrophoresis in sodium dodecyl sulfate was performed according to Laemmli's procedure [25] that was described in Ref. [26], except that no 2-mercaptoethanol was added to avoid the possible detachment of bound arsenic species from membrane proteins. The destained gels were scanned on a CS-9301 PC dual-wavelength flying spot scanning densitometer (Shimazu, Japan) at $580 \mathrm{~nm}$.

\subsection{Spin-labeling ESR study}

After incubation of erythrocytes ( $200 \mu 1,40 \%$ hematocrit) with solutions containing arsenite, arsenate or vanadate in 
PBS ( $800 \mu \mathrm{l}$ at various concentrations) at $36.5 \pm 1{ }^{\circ} \mathrm{C}$ for 5 $\mathrm{h}$, the cells were packed and the supernatant removed. Then 5DS or 16DS in PBS was added to the cells and the mixture incubated at $0-4{ }^{\circ} \mathrm{C}$ overnight. The excess labels were washed out with PBS immediately before the ESR measurement. The cells were placed in a quartz capillary tube and the ESR spectra were recorded with a Bruker EPR 300 spectrometer at room temperature $\left(\sim 25^{\circ} \mathrm{C}\right)$. The order parameter $S$ and the rotational correlation time $\tau_{\mathrm{c}}$ were calculated from spectra of 5DS and 16DS labeled samples, respectively, according to Eqs. (2)-(5) [27]:

$S=0.568 \times\left(A_{\|}-A_{\perp}\right) /\left[\left(A_{\|}+A_{\perp}\right) / 3\right]$

where $A_{\|}$and $A_{\perp}$ are parallel and perpendicular parts of the hyperfine splitting corresponding to one-half of the separation of the outer peaks and the inner peaks in a spectrum, respectively.

$\tau_{\mathrm{c}}\left(\mathrm{m}^{2}\right)=6.51 \times 10^{-10} \delta H_{0}[R(-1)+R(+1)-2]$

$R(-1)=[h(0) / h(-1)]^{1 / 2}$

$R(+1)=[h(0) / h(+1)]^{1 / 2}$

where $\delta H_{0}$ is the peak-to-peak linewidth (in G) of the central peak of an ESR spectrum, and $h(0), h(-)$ and $h(+)$ are the line-heights of peaks in the central, higher and lower fields, respectively.

\subsection{The erythrocyte population in an electric field}

The erythrocyte population in an electric field was examined in a BIO-RAD Rotofor ${ }^{\circledR}$ cell (Bio-Rad). Between the positive and negative electrodes, 20 grids were fixed to a rotatory axis and separated from each other by membranes with $10 \mu \mathrm{m}$ diameter holes. The grids were fully filled with LISIB. The erythrocytes, after being incubated with arsenite, arsenate or vanadate and washed, were placed into the sixth grid to the negative electrode. The axis was made to rotate slowly to avoid the sediment in the cells. In an electric field with a gradient of $4 \mathrm{~V} / \mathrm{cm}$, the erythrocytes were left to migrate for $1 \mathrm{~h}$. The solution in each and every grid was then

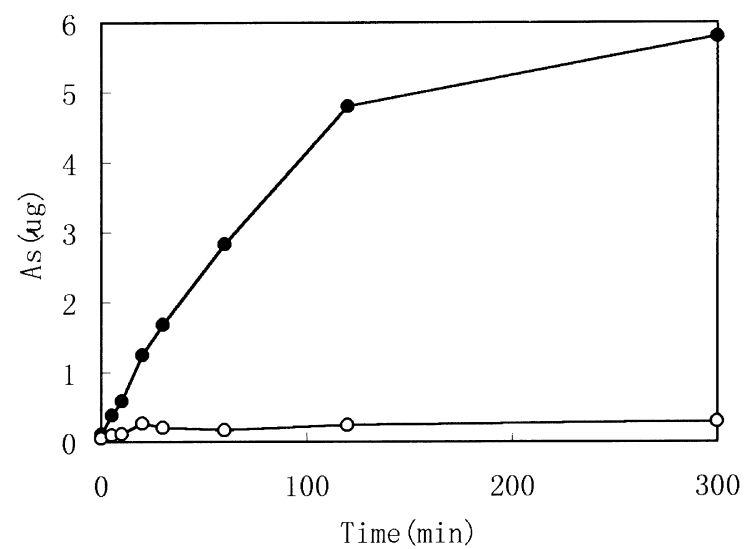

Fig. 1. Time dependence of intracellular arsenic in arsenate-human erythrocyte incubation system without $(\bullet)$ and with $(\bigcirc)$ DIDS. pumped out simultaneously and collected separately for the subsequent measurement of absorbance at $414 \mathrm{~nm}$ on a spectrophotometer (Hitachi, Japan). Finally, the $\mathrm{pH}$ values of the solutions in the grids between the fourth and the sixteenth were checked and were found to be in the range 6.5-8.

\section{Results}

\subsection{Transport and inhibition of arsenite and arsenate}

In the arsenate incubation system, the temporal change in the intracellular arsenic approached the highest $(5.8 \mu \mathrm{g}$, $\sim 0.2 \mathrm{mM}$ ) in $5 \mathrm{~h}$ (Fig. 1, curve ). The transport was strongly inhibited (95\%) by DIDS (Fig. 1, curve $\bigcirc$ ), an inhibitor to the band 3 protein in the membrane [28], indicating that arsenate passed across the human erythrocyte membrane through the anion exchange system [29].

Arsenite entered the cells much more rapidly (Fig. 2) than arsenate. The intracellular concentration of arsenic reached its maximum $(12.26 \mu \mathrm{g}, \sim 0.41 \mathrm{mM})$ within $30 \mathrm{~min}$. In contrast to arsenate, the arsenite influx into human erythrocytes was not inhibited by DIDS, suggesting that arsenite passed across the membrane by a different route.

\subsection{Binding of arsenite and arsenate to HEM}

In the course of arsenite transport, no decline was observed in the amount of arsenic bound to the intact cells (Fig. 3, curve $\mathbf{\square})$, and the membrane-bound arsenic increased after a lag of about $30 \mathrm{~min}$ (Fig. 3, curve $\boldsymbol{\Delta}$ ). The lag is comparable with the time elapsed before the drop in the amount of intracellular arsenic in Fig. 2.

In the case of arsenate, the time dependence of the amount of arsenic in the membrane and bound to the intact cells is presented in Fig. 4. The content of membrane-bound arsenic was quite high $(\sim 1 \mu \mathrm{g})$ at the beginning, and it rose again after a drop to about $0.4 \mu \mathrm{g}$ (Fig. 4 , curve $\triangle$ ). During this period, the amount of arsenic with intact cells increased steadily to a limit (Fig. 4, curve $\square$ ).

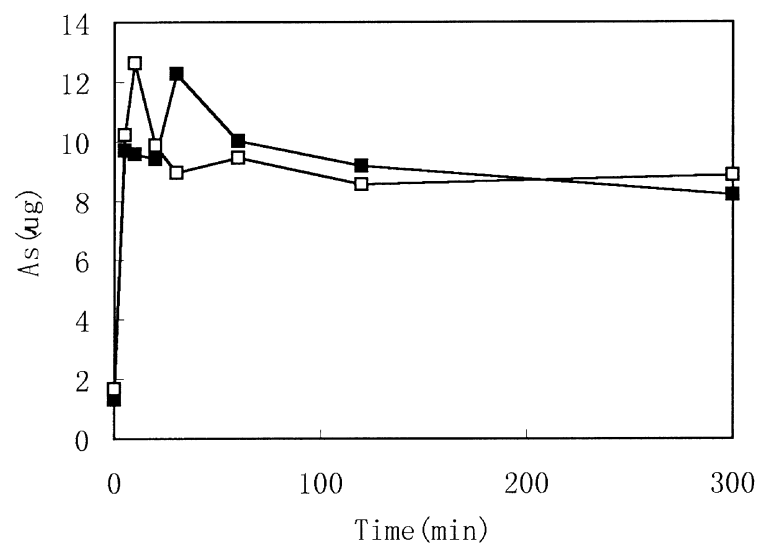

Fig. 2. Time dependence of intracellular arsenic in arsenite-human erythrocyte incubation system without ( $\square)$ and with ( $\square$ ) DIDS. 


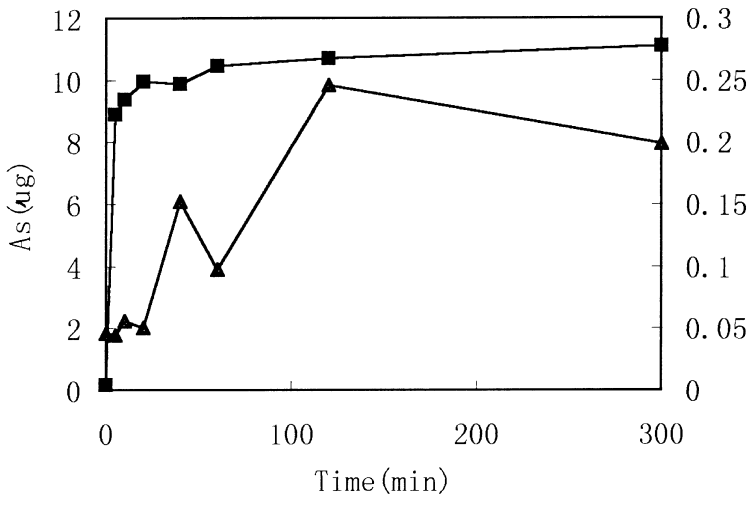

Fig. 3. Time dependence of the amount of arsenic in intact cells ( $\square$ to the left ordinate) and in the membrane ( $\boldsymbol{\Delta}$ to the right ordinate) in the arsenitehuman erythrocyte incubation system.

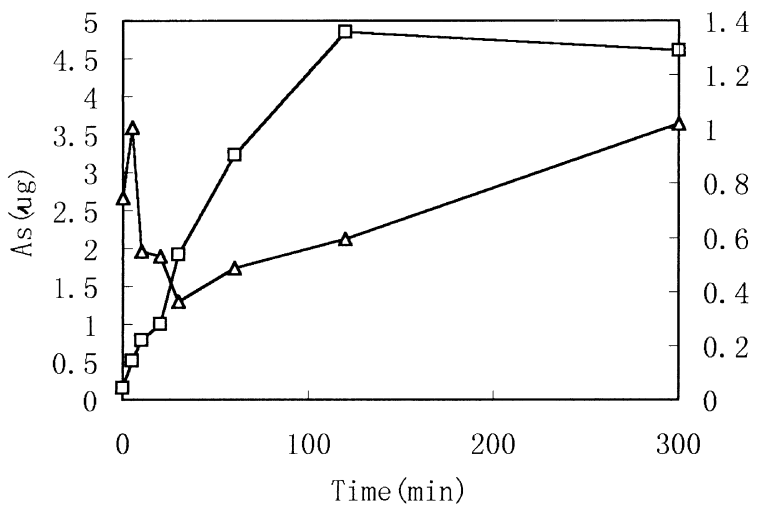

Fig. 4. Time dependence of the amount of arsenic in intact cells ( $\square$ to the left ordinate) and in the membrane ( $\triangle$ to the right ordinate) in the arsenatehuman erythrocyte incubation system.

\subsection{Hemolysis}

The results from experiments run over $24 \mathrm{~h}$ showed that the $\mathrm{H} \%$ was less than $1 \%$ in $15 \mathrm{~h}$ regardless of the absence or presence of arsenite, arsenate or vanadate (Fig. 5). However, hemolysis began to increase dramatically in all cases hereafter.

\subsection{Consumption of sulfhydryl in the membrane by arsenite, arsenate and vanadate}

The sulfhydryl in the membrane became undetectable after incubating ghosts with these anions. However, the addition of SDS to the membrane suspensions to a final concentration of $0.5 \%(\mathrm{w} / \mathrm{v})$ made the sulfhydryl detectable, and the amount of sulfhydryl in the treated ghosts was less than in the control (Fig. 6).

\subsection{Disturbance of the protein assembly in the membrane by arsenite, arsenate and vanadate}

The scanning of the SDS-PAGE gel revealed that, after incubation of ghosts with arsenite, arsenate and vanadate, the proteins, bands 1 and 2, changed significantly (Fig. 7). The

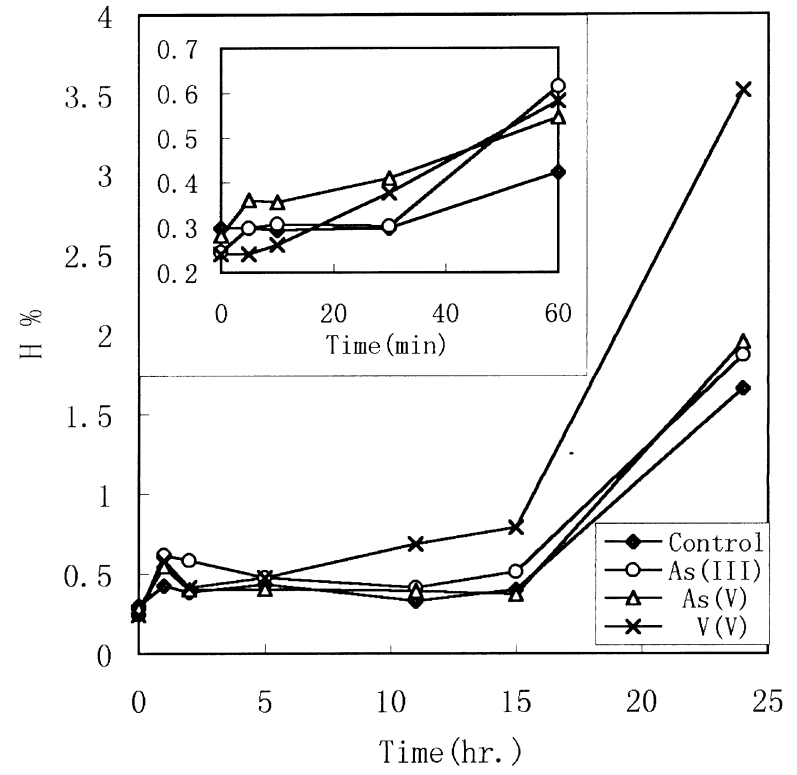

Fig. 5. Temporal courses of percent hemolysis of human erythrocytes incubated with arsenite, arsenate and vanadate, respectively.

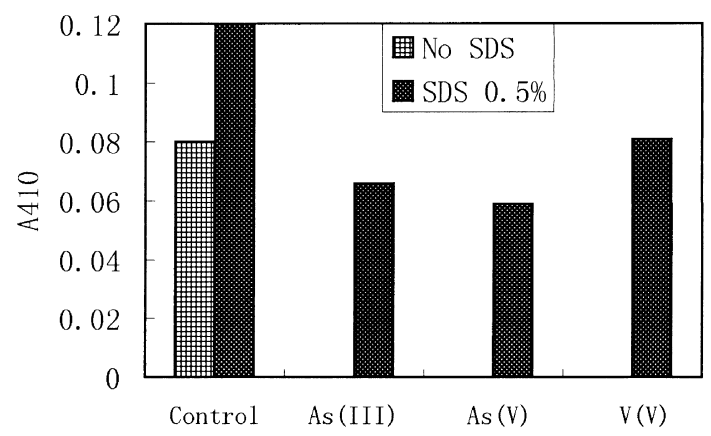

Fig. 6. Effect of arsenite, arsenate and vanadate on the sulfhydryl level of the human erythrocyte membrane.

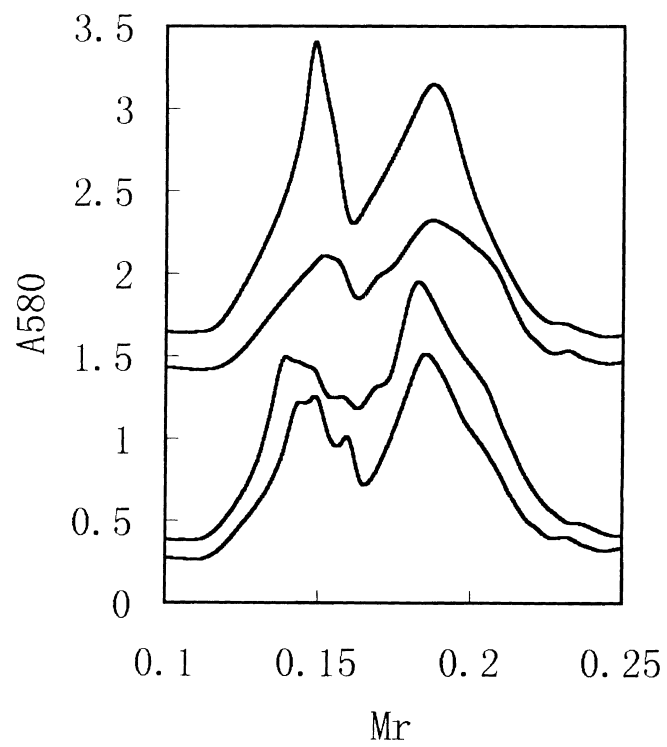

Fig. 7. Profiles of the proteins band 1 (left peak) and band 2 (right peak) after SDS-PAGE and scanned at $580 \mathrm{~nm}$. The abscissa represents the relative mobility of the protein on the gel. From up to down: the membrane was incubated with arsenite, arsenate and vanadate, respectively, and the control. 

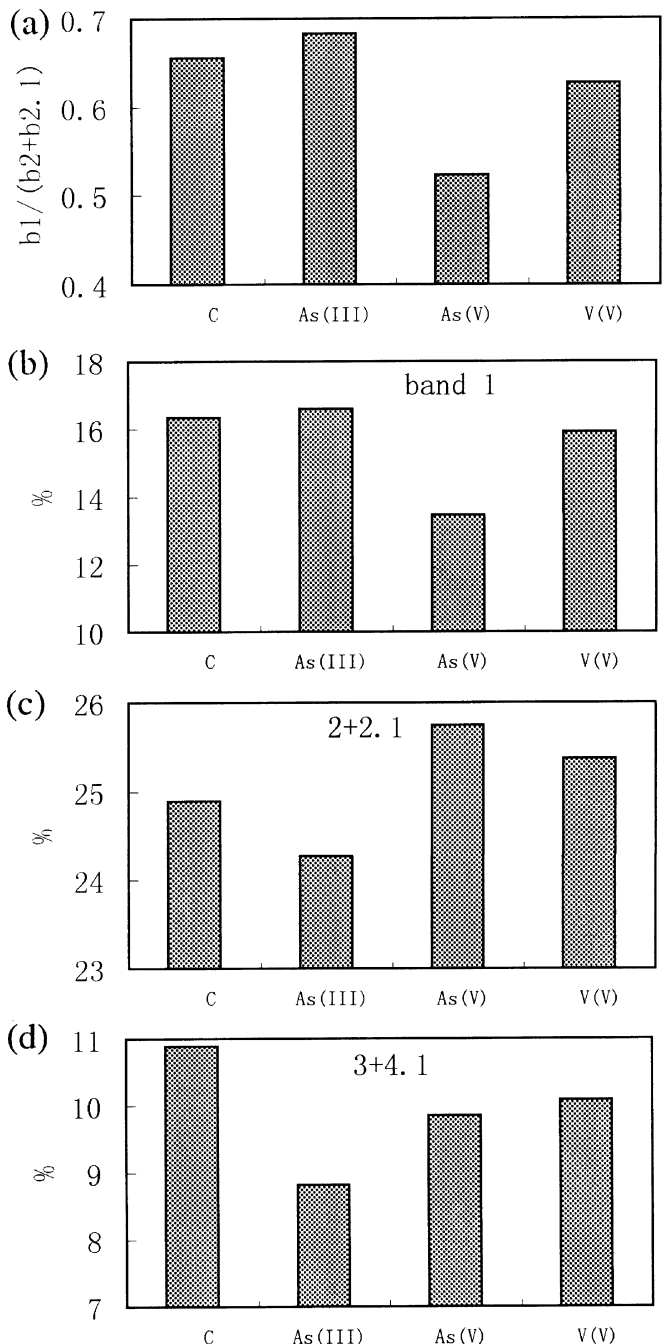

Fig. 8. Changes in the amount of membrane proteins after incubation of human erythrocyte ghosts with arsenite, arsenate and vanadate, respectively.

integration of the areas under the peaks indicates that arsenite caused a decrease in the amount of band 2 (Fig. 8(c)) which accounted for the increase in the area ratio of band 1 to band 2 (Fig. 8(a)). Quite differently, arsenate made the ratio smaller by decreasing band 1 (Fig. 8(b)). Vanadate's effect on bands 1 and 2 was less significant. Moreover, arsenite also caused a fall in the amount of band 3 (Fig. 8(d)), though its transport across the membrane was not mediated by this protein. Because band 4.1 was very close to band 3 in the gel and its amount was much less than that of band 3, it was also presented along with band 3 in Figs. 8(d) and 9(d).

The results from the incubation of intact erythrocytes with arsenite and vanadate are different from those of ghosts. As revealed in Fig. 9, the protein most affected by arsenite was band 1 , instead of bands 2 and 3. Vanadate stabilized band 2 against detachment from the membrane while it destabilized band 3. As for arsenate, its effect on these proteins was essentially the same as that with ghosts, though to varying extents.
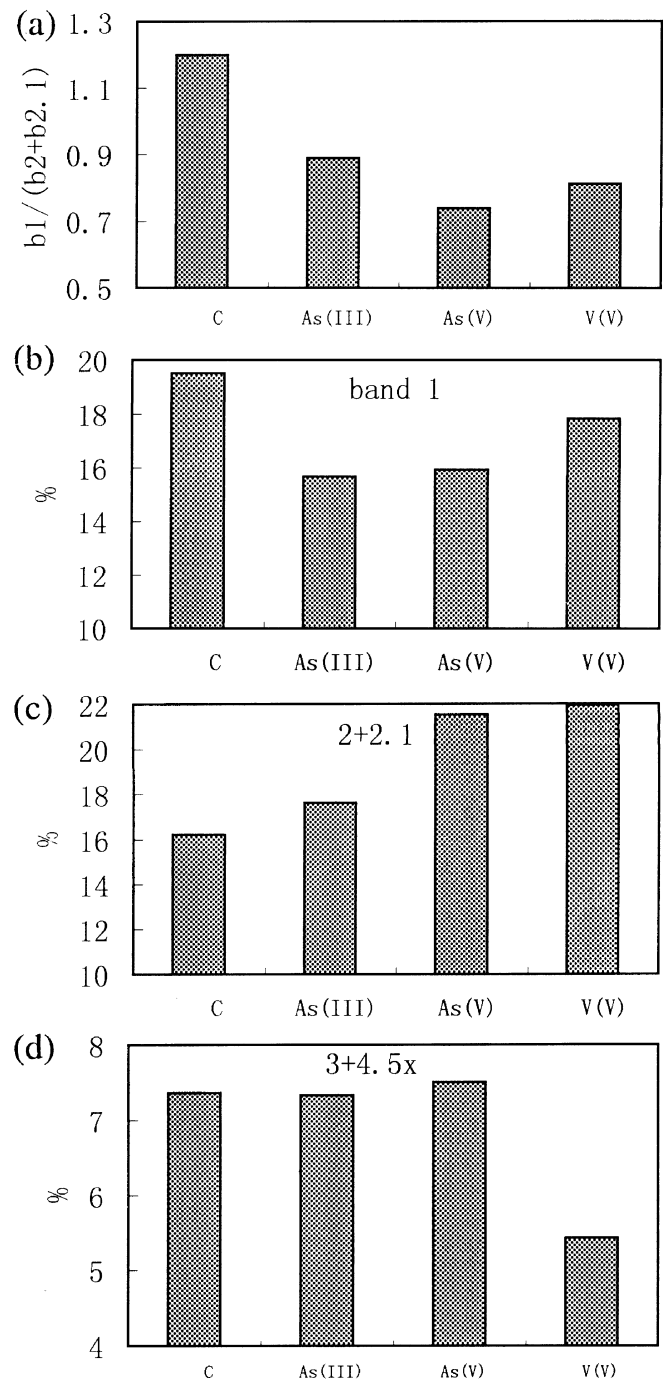

Fig. 9. Changes in the amount of membrane proteins after incubation of human erythrocytes with arsenite, arsenate and vanadate, respectively.

\subsection{Decrease in membrane fluidity caused by arsenite, arsenate and vanadate}

The effect of arsenite, arsenate and vanadate on the fluidity of the membrane lipid of human erythrocytes has been evaluated with the spin-labeling ESR technique. The order parameter $S$, defined for high frequency motions, depends on the amplitudes of molecular motions that take place with frequencies higher than $\sim 1 / \pi T$, where $T$ is a characteristic time determined by the reciprocal of the anisotropy of the hyperfine interaction and Zeeman interactions, in frequency units [30]. The rotational correlation time can be considered as the time required for the molecule to forget its previous spatial orientation [31]. Both $S$ and $\tau_{\mathrm{c}}$ are in reverse proportions to the fluidity of the membrane lipid, but they reflect the fluidity at different depths: the doxyl radical of the 5DS molecule stays close to the outer surface of the cell membrane, while that of 16DS inserts itself into the middle of the lipid bilayer. The magnitudes of $S$ and $\tau_{\mathrm{c}}$, therefore, reflect the local fluidity 
in different depths. As revealed in Fig. 10, the membrane fluidity both on the surface and in the middle dropped after the treatment, and the effect was in the following order: $\mathrm{VO}_{4}{ }^{3-}>\mathrm{AsO}_{4}{ }^{3-}>\mathrm{AsO}_{3}{ }^{3-}$.

\subsection{Decrease in negative charge density on the outer surface of the membrane}

The change in the charge density on the outer surface of the membrane was examined by measuring the population of cells after their migration for $1 \mathrm{~h}$ in an electric field (Fig. 11). Compared with the control, cells between the sixth and eighth grids increased after incubating the cells with arsenite, arsenate and vanadate, respectively, while the number of cells moving rapidly became less. According to the percentage of
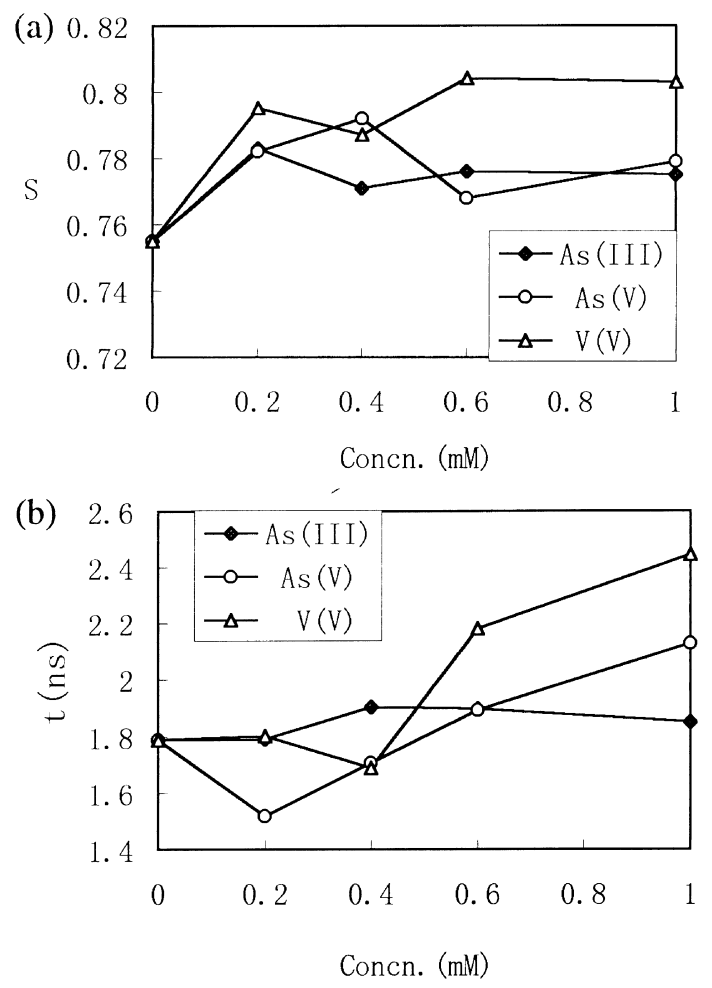

Fig. 10. Dependences of the order parameter $S$ and the rotational correlation time $\tau_{\mathrm{c}}$ on the concentrations of arsenite, arsenate and vanadate, respectively.

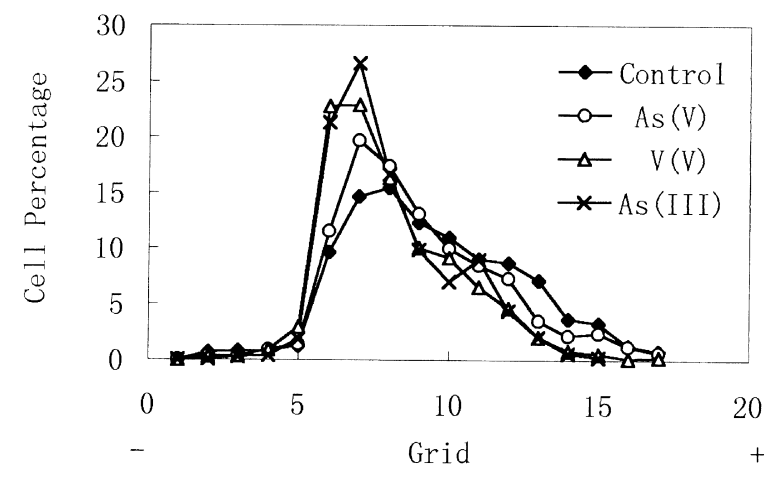

Fig. 11. Population of human erythrocytes in an electric field. The cells were placed into the sixth grid to the negative electrode. the slowly moving cells, the effect was in the following order: $\mathrm{AsO}_{3}{ }^{3-}>\mathrm{VO}_{4}{ }^{3-}>\mathrm{AsO}_{4}{ }^{3-}$.

\section{Discussion}

\subsection{Arsenate transports into human erythrocytes through anion exchange protein}

The time course of the change in the amount of arsenic in human erythrocyte cytosol (Fig. 1, curve - is similar to those from Delnomdedieu et al. [32] using rabbit erythrocytes. These authors reported that $53 \%$ of the total arsenic entered the cells in $5 \mathrm{~h}$ and a complete equilibrium would need more than $24 \mathrm{~h}$. However, the results from an in vivo experiment provided by Vahter and Norin [11] using mice are quite different. In mice that were given orally a high dose arsenate ( $4 \mathrm{mg} \mathrm{As} / \mathrm{kg}$ body weight), the highest amount of arsenic in erythrocytes was reached at about the second hour from administration. By then the ratio of intracellular arsenic to that in plasma was close to unity. The amount of arsenic decreased henceforth as a slow clearance phase.

The inhibition of arsenate transport by DIDS (Fig. 1, curve O) indicates that, arsenate, similar to vanadate that competes with phosphate [17], passes HEM through the anion exchange protein, band 3 . This inference is also supported by results from Kenney and Kaplan [33]. In their experiment, the inhibition extent (77-80\%) of arsenate efflux from resealed human erythrocyte ghosts by DNDS (4,4'-dinitro-2,2' stilbenedisulfonic acid) was close to that $(82-87 \%)$ of phosphate. A recent report from Huang and Lee [34] demonstrated that arsenate uptake by KB cells was dose-dependently inhibited by phosphate, suggesting that arsenate and phosphate did share a common transport system. Our result now confirms the same transport mechanism in intact human erythrocytes. Indeed the behaviors of some extrinsic species are similar to certain intrinsic species [15,17-20,33-36].

There is, however, a difference between arsenate and vanadate, though both of them are phosphate analogs. Vanadate transport could be described as a double-exponential process with the faster phase corresponding to the vanadate equilibration across the membrane and with the slower one corresponding to the vanadate accumulation in the cytoplasm [17]. For arsenate, no such definite phases were observed, showing the disparity between arsenate and vanadate in their behaviors in the pathway and in the cytosol. The overlap of three processes, i.e., transport, bio-transformation in the cytosol and binding to the membrane (which we shall discuss later), accounts for the absence of distinct phases in the arsenate transport.

\subsection{Arsenite transports into human erythrocytes by diffusion}

Arsenite transports into human erythrocytes more rapidly (Fig. 2, curve ) than arsenate and was not mediated by the 
anion exchange protein (Fig. 2, curve $\square$ ). These results are consistent with those from Delnomdedieu et al. [32] using rabbit erythrocytes and those from Huang and Lee [34] using human oral epidermal carcinoma KB cells. The easier access of arsenite to these cells has been interpreted by the passive diffusion of zero-charged $\mathrm{As}(\mathrm{III})$ species, $\mathrm{As}(\mathrm{OH})_{3}$, in physiological $\mathrm{pH}$ [36]. Since the initial uptake rate of arsenite was linearly correlated with its extracellular concentration, arsenite probably entered erythrocytes through simple diffusion [34]. Wang et al. [14] have recently reported the existence of an energy-dependent arsenite pump in some Chinese hamster cell variants, demonstrating that arsenite extrusion by the arsenic pump is not the exclusive way of detoxification to bacterial cells. Considering the much more rapid uptake rate of arsenite than that of arsenate (passing across the membrane through the anion exchange system) and that of MMA and DMA (by diffusion), it seems too early to rule out other transport mode(s).

A unique feature of the uptake kinetics of arsenite is the drop after the initial rise in the first $30 \mathrm{~min}$. This characteristic profile is very reproducible. Delnomdedieu et al. [32] were unable to observe the phenomenon, possibly due to their large time interval in sampling. In the data shown by Huang and Lee [34], however, a drop in the kinetic curve did appear when the initial arsenic concentration in the bulky solution was above $500 \mu \mathrm{M}$. What has happened to the arsenite that has just entered the cells?

\subsection{Arsenite binds to the erythrocyte membrane from cytosol}

Since the amount of arsenic with intact cells did not decrease (Fig. 3, curve $\mathbf{\square}$ ), the outward movement of the arsenic species in the cytosol can be excluded. Hence the "lost arsenic' from the cytosol must have bound to the membrane. We did observe the membrane-bound arsenic and found a time lag of about 30 min before the increase in the amount of arsenic in the membrane (Fig. 3, curve $\mathbf{\Delta}$ ). The coincidence between the increase of the membrane-bound arsenic and the decrease of the intracellular arsenic is strong evidence for the binding of arsenite from cytosol.

Furthermore, if the membrane-bound species had been arsenite, it would have bound while passing through the membrane and no time lag would have been observed. Therefore, it must be the transformed arsenic species that bound to HEM from the cytoplasmic side, decreasing the amount of arsenic in cytosol.

\subsection{Binding, releasing and re-binding of arsenate}

The interaction between arsenate and erythrocyte membrane is complex. The relatively high level of membrane-bound arsenic at the beginning (Fig. 4, curve $\triangle$ ) implies a rapid binding of arsenate from the bulky solution to the membrane. The binding is too rapid to follow by means of the present analysis. The subsequent decline in the amount of arsenic suggests that some of the membrane-bound arsenic species is released from the membrane and that the vacancies were not refilled equally by arsenate successors. This is probably due to the binding-induced conformational change of the proteins, which made these vacancies no longer accessible to arsenate in the bulky solution. The release after rapid binding might also result from the transfer of arsenate from kinetically favored binding sites in the membrane to thermodynamically more stable ones in both membrane and cytosol. It has been known that arsenate can be enzymatically reduced to As(III) in rat erythrocytes [13]. If the reduction could also take place in human erythrocytes, the As(III) binding from cytosol would also contribute to the last rising phase of the curve.

While the membrane was experiencing the binding, releasing and re-binding of arsenate, the amount of arsenic in cytosol (Fig. 1, curve ) and with the intact cells (Fig. 3, curve $\bigcirc)$ increased steadily, indicating that the anion exchange protein, band 3, had not been affected. A more detailed discussion on some membrane proteins will be given in Section 4.7.

\subsection{Hemolysis}

Parallel experiments were run under the same conditions as those for transport experiments. The percent hemolysis was found less than $1 \%$ in even $15 \mathrm{~h}$ in the presence of arsenite, arsenate and vanadate, respectively. Since all transport and inhibition experiments were run within $5 \mathrm{~h}$, the influence of hemolysis was negligible. However, it is noteworthy that hemolysis can be greatly aggravated by disturbing the cells, e.g., swinging the test-tube or stirring the cells during incubation. It seems that the cell membrane is made more fragile by the treatment with arsenite, arsenate or vanadate.

\subsection{Arsenite, arsenate and vanadate consume sulfhydryl groups of membrane proteins}

The arsenic binding sites in the membrane are believed to be the sulfhydryl groups of the membrane proteins, since, except for the control, the sulfhydryl level of the membrane became undetectable after the incubation with arsenite, arsenate and vanadate, respectively (Fig. 6). The change brought about by the addition of SDS implies: first, that some of the protein sulfhydryls are readily available to DTNB (Section 2.5), as well as to arsenite, arsenate and vanadate; secondly, that other sulfhydryls are buried in the lipid and/or the hydrophobic core of membrane proteins. Because the quantities of sulfhydryl in the membrane incubated with arsenite, arsenate or vanadate were less than the increment in the control after the addition of SDS, both kinds of sulfhydryl groups, including all the former and part of the latter, were involved in the binding of arsenite, arsenate and vanadate. The disulfide bond cannot be broken by arsenite, arsenate or vanadate under the experimental conditions, as examined with the oxidized form 
of glutathione (data not shown), so the involvement of disulfide in the binding can be excluded. According to Jacob and Jandl [37], it is ultimately the membrane sulfhydryl activity, but not the intracellular activity, that decides the shape and integrity of red cells exposed to sulfhydryl inhibitors in vitro. The disturbance of membrane peripheral and integral proteins (e.g., bands 1, 2 and 3) could be taken as evidence for the damage in membrane integrity, which we shall discuss later.

\subsection{Arsenite, arsenate and vanadate disturb protein assembly in the membrane}

The binding of arsenite, arsenate and vanadate on to HEM would lead to the interruption of the membrane architecture. Bands 1, 2 and 3 are among the most abundant proteins in HEM [16]. A dimer of band 1 and a dimer of band 2 form a tetramer, the tetramers then connect with each other and form oligomers. Bands 1 and 2 make up the major constituents of the membrane skeleton and, accordingly, are classified into peripheral proteins. On the other hand, band 3 traverses the membrane more than ten times and belongs to integral protein. Band 3 functions as a $\mathrm{HCO}_{3}{ }^{-} / \mathrm{Cl}^{-}$exchanger of erythrocytes and, as discussed in Section 4.1, arsenate and vanadate passed erythrocyte membrane through the protein. Figs. 7-9 show that these proteins were among the targets for attack from these extrinsic species and that they were affected to different extents. The changes observed in SDS-PAGE reflect the changes in the stability of the oligomers and in their attachment to the intrinsic proteins in the membrane skeleton.

The incubation of ghosts (Fig. 8) and the intact cells (Fig. 9) resulted in different effects on the three main proteins in the membrane, providing evidence for the participation of cytosol in the interaction of arsenite and vanadate with the cell membrane. These results are consistent with that discussed in Section 4.3. In that case, the membrane-bound arsenic was a product of the reaction between arsenite and cytoplasmic substance( $\mathrm{s}$ ).

Those proteins which bound arsenite or arsenate but were no longer with the membrane, would not make any contribution to the amount of membrane-bound arsenic in our experiments. In all the incubation systems of intact cells, the amount of band 1 decreased and that of band 2 increased. Since the protein band 2 was relatively stable and did not detach from the membrane, it could be one of the main proteins to which arsenate and transformed arsenite species bound in the incubation systems of intact cells.

The results shown in Figs. 8(d) and 9(d) imply the existence of a protective function of cytosol against the effects of arsenite and arsenate for the anion exchange protein, band 3 . In contrast with arsenite and arsenate, vanadate affected band 3 only in the incubation system of intact cells.

\subsection{Arsenite, arsenate and vanadate affect fluidity and surface charge of the membrane}

Presented in Fig. 10 are the concentration dependences of the order parameter $S$ and the rotational correlation time $\tau_{\mathrm{c}}$.
Each of the three extrinsic species caused a slight reduction in fluidity of the membrane lipids. Since no strong interaction of arsenite, arsenate and vanadate with membrane lipids is expected, the change in membrane fluidity may be a consequence of their interaction with membrane proteins.

Normal erythrocytes are negatively charged on their outer surface to prevent them from aggregation with each other and from adhesion to the wall of blood vessels. The interaction of arsenite, arsenate and vanadate with HEM must have profoundly changed the tertiary and quaternary structures of the membrane proteins, otherwise the simple binding of the anions would have increased the negative charge density on the outer surface of the cells and, consequently, made cells move more easily towards the positive electrode. The less negative character, together with the lower fluidity (Fig. 10) and the increased fragility (Section 4.7), may contribute to diseases related to abnormal blood rheological properties.

\section{Acknowledgements}

This work was supported by the National Natural Science Foundation of China. We thank Professor Ya-Xian Su for helpful discussions on some of the experimental results.

\section{References}

[1] O.M.N. Dhubhghaill, P.J. Sadler, Struct. Bonding 78 (1991) 130190.

[2] IARC, Arsenic and Arsenic Compounds. Monographs on the Evaluation of Carcinogenic Risk of Chemicals to Humans. vol. 23, WHO, Lyon, 1980, pp. 37-141.

[3] D.P. Lu, J.Y. Qui, S.S. Chen, et al., Blood 90 (1997) 416a.

[4] J. Dai, R.S. Weinberg, S. Waxman, et al., Blood 93 (1999) 268-277.

[5] Y.M. Li, J.D. Broome, Cancer Res. 59 (1999) 776-780.

[6] P. Rousselot, S. Labaume, J.P. Marolleau, et al., Cancer Res. 59 (1999) 1041-1048.

[7] G.Q. Chen, J. Zhu, Z. Chen, et al., Blood 88 (1996) 1052-1061.

[8] C. Xu, T. Zhou, M. Kuroda, et al., J. Biochem. (Tokyo) 123 (1998) $16-23$.

[9] S. Silver, J. Ind. Microbiol. Biotechnol. 20 (1998) 1-12.

[10] S.M. Healy, E.A. Casarez, H.V. Aposhian, et al., Toxicol. Appl. Pharmacol. 148 (1998) 65-70.

[11] M. Vahter, H Norin, Environ. Res. 21 (1980) 446-457.

[12] D.J. Thompson, Chem.-Biol. Interact. 88 (1993) 89-114.

[13] S.L. Winski, D.E. Carter, J. Toxicol. Environ. Health 46 (1995) 379397.

[14] Z. Wang, S. Dey, T.G. Rossman, Toxicol. Appl. Pharmacol. 137 (1996) 112-119.

[15] S.L. Winski, D.E. Carter, J. Toxicol. Environ. Health, Part A 53 (1998) 345-355.

[16] H. Schenkel-Brunner, Human Blood Groups: Chemical and Biochemical Basis of Antigen Specificity, Springer, Berlin, 1995, Ch. 4.

[17] L.C. Cantley Jr., M.D. Resh, G. Guidotti, Nature 272 (1978) 552554.

[18] M. Mosior, T. Krawczak-Sadowska, H.J. Gomulkiewicz, Gen. Physiol. Biophys. 11 (1992) 337-343.

[19] G. Repetto, P. Sanz, M. Repetto, Toxicology 92 (1994) 143-153.

[20] M. Vahter, E. Marafante, Chem.-Biol. Interact. 47 (1983) 29-44.

[21] H. Sigel, A. Sigel, Metal Ions in Biological Systems, vol. 31, Marcel Dekker, New York, 1995. 
[22] D.M. Shotton, in: J.E. Celis (Ed.), Cell Biology. A Laboratory Handbook, 2nd ed., Academic Press, San Diego, 1998, pp. 26-33.

[23] O.H. Lowry, N.J. Rosebrough, A.L. Farr, et al., J. Biol. Chem. 193 (1951) 256-275.

[24] G.L. Ellman, Arch. Biochem. Biophys. 82 (1959) 70-77.

[25] U.K. Laemmli, Nature 227 (1970) 580-685.

[26] J.F. Robyt, B.J. White, Biochemical Techniques: Theory and Practice, Brooks/Cole, Monterey, CA, 1987, pp. 143-145.

[27] G. Lenay, in: R.A. Capald (Ed.), Membrane Proteins and Their Interaction with Lipid, Academic Press, New York, 1977, p. 47.

[28] S. Ship, Y. Shami, W. Breuer, J. Membrane Biol. 33 (1977) 311323.

[29] M.J.A. Tanner, J. Membrane Biol. 14 (1997) 155-165.
[30] H.M. McConnell, in: L.J. Berliner (Ed.), Spin Labeling: Theory and Applications, Academic Press, New York, pp. 542-543.

[31] I.C.P. Smith, in: H.M. Swartz, J.R. Bolton, D.C. Borg (Eds.), Biological Applications of Electron Spin Resonance, Wiley, New York, p. 491.

[32] M. Delnomdedieu, M. Styblo, D.J. Thomas, Chem.-Biol. Interact. 98 (1995) 69-83.

[33] L.J. Kenney, J.H. Kaplan, J. Biol. Chem. 263 (1988) 7954-7960.

[34] R.-N. Huang, T.-C. Lee, Toxicol. Appl. Pharmacol. 136 (1996) $243-$ 249.

[35] K. Wang, S. Afr. Tydskr. Chem. 50 (1997) 232-239.

[36] M. Delnomdedieu, M.M. Basti, M. Styblo, et al., Chem. Res. Toxicol. 7 (1994) 621-627.

[37] H.S. Jacob, J.H. Jandl, J. Clin. Invest. 41 (1962) 779-792. 